\title{
Student progress decision-making in programmatic assessment: can we extrapolate from clinical decision-making and jury decision-making?
}

Mike Tweed $^{1 *}$ (D) and Tim Wilkinson ${ }^{2}$

\begin{abstract}
Background: Despite much effort in the development of robustness of information provided by individual assessment events, there is less literature on the aggregation of this information to make progression decisions on individual students. With the development of programmatic assessment, aggregation of information from multiple sources is required, and needs to be completed in a robust manner. The issues raised by this progression decisionmaking have parallels with similar issues in clinical decision-making and jury decision-making.

Main body: Clinical decision-making is used to draw parallels with progression decision-making, in particular the need to aggregate information and the considerations to be made when additional information is needed to make robust decisions. In clinical decision-making, diagnoses can be based on screening tests and diagnostic tests, and the balance of sensitivity and specificity can be applied to progression decision-making. There are risks and consequences associated with clinical decisions, and likewise with progression decisions.

Both clinical decision-making and progression decision-making can be tough. Tough and complex clinical decisions can be improved by making decisions as a group. The biases associated with decision-making can be amplified or attenuated by group processes, and have similar biases to those seen in clinical and progression decision-making. Jury decision-making is an example of a group making high-stakes decisions when the correct answer is not known, much like progression decision panels. The leadership of both jury and progression panels is important for robust decision-making. Finally, the parallel between a jury's leniency towards the defendant and the failure to fail phenomenon is considered.

Conclusion: It is suggested that decisions should be made by appropriately selected decision-making panels; educational institutions should have policies, procedures, and practice documentation related to progression decision-making; panels and panellists should be provided with sufficient information; panels and panellists should work to optimise their information synthesis and reduce bias; panellists should reach decisions by consensus; and that the standard of proof should be that student competence needs to be demonstrated.
\end{abstract}

Keywords: Programmatic assessment, Decision-making, Policy

\footnotetext{
* Correspondence: mike.tweed@otago.ac.nz

${ }^{1}$ Department of Medicine, University of Otago Wellington, Wellington, New

Zealand

Full list of author information is available at the end of the article
}

(c) The Author(s). 2019 Open Access This article is distributed under the terms of the Creative Commons Attribution 4.0 International License (http://creativecommons.org/licenses/by/4.0/), which permits unrestricted use, distribution, and reproduction in any medium, provided you give appropriate credit to the original author(s) and the source, provide a link to the Creative Commons license, and indicate if changes were made. The Creative Commons Public Domain Dedication waiver (http://creativecommons.org/publicdomain/zero/1.0/) applies to the data made available in this article, unless otherwise stated. 


\section{Background}

\section{The problem with decision-making in assessment}

Much effort has been put into the robustness of data produced by individual assessments of students. There is an extensive literature on achieving robustness of assessment data at the individual test or assessment event level, such as score reliability, blueprinting, and standard setting [1$3]$. This is especially so for numerical data [4], but increasingly also for text/narrative data [5]. However, decisions are more often made by considering a body of evidence from several assessment events. This is increasingly the case as a more programmatic approach to assessment is taken [6]. For example, the decision on passing a year is becoming less about a decision on passing an end of year examination and more about a decision based on synthesising assessment results from across an entire year. Despite these changes, there is a gap regarding the pitfalls and ways to improve the aggregation of information from multiple and disparate individual assessments in order to produce robust decisions on individual students [7].

In this paper we draw parallels between student progression decision-making and clinical decision-making, and then within the context of decisions a made by groups, we will draw parallels between progression decision-making and decision-making by juries. Finally, exploration of these parallels leads to suggested practical points for policy, practice and procedure with regard to progression decision-making. There are many examples of decision-making that could be used but we chose clinical decision-making as it is familiar to healthcare education institutions, and jury decision-making as it is a relevant example of how groups weigh evidence to make high-stakes decisions.

\section{Progression decision-making: parallels in clinical decision- making}

The decision-making around whether a student is ready to progress (pass) or not (fail) has many parallels with patient diagnosis [8]. For both assessment progression decisions and patient diagnosis decisions, several pieces of information (a mix of numerical and narrative/text with varying degrees of robustness), need to weighed up and synthesised. Patient diagnosis decisions and subsequent decisions on management can be high-stakes in terms of impact on the patient and/or healthcare institution. Likewise progression decisions and the consequences carry high-stakes for students, educational institutions, healthcare institutions, patients, and society.

\section{Aggregating information to make decisions}

Clinicians and clinical teams combine various pieces of information efficiently and accurately using heuristics [9-14], however clinical decision-making regarding patient diagnoses can be prone to biases and inaccuracies
[12, 15-18]. Just as metacognitive awareness of such biases and errors $[15,16]$ is postulated to lead to improved clinical decision-making [19-21], we suggest that an awareness of such biases in combining assessment information, and ways to address this, could also improve the robustness of progression decisions.

\section{Gathering information}

In the clinical setting, data used to inform the decision-making of a patient diagnosis may come from the consultation and associated investigations. The history is almost entirely narrative/text, the clinical exam is mostly narrative/text with some numerical data, and investigations are a mixture of narrative/text and numerical data. Clinical decision-making leading to a diagnosis can be quick and efficient [15], but sometimes it is more difficult and the clinician may need to obtain more information, weigh up different options, and/or weigh up conflicting pieces of evidence.

The process of obtaining additional information may include repeating data collection, e.g. revisiting the consultation and investigations; approaching the issue from a different perspective, e.g. obtaining a computerised tomography scan to complement a plain radiograph; and/or looking for an entirely new and different source of information, e.g. getting a biopsy [15]. The nature of this additional information will depend on the information obtained so far, as doing the same extra tests on all patients regardless of what is already known is not good clinical practice. Consideration is also given to the most appropriate investigations in terms of efficiency, risk/benefit, and cost [22, 23], to answer the clinical question posed.

In clinical decision-making it is inefficient, and sometimes harmful, to keep collecting data or undertaking investigations once a diagnosis is secure. There are parallels with this, in terms of progression decision-making: obtaining additional information to inform progression decision-making may include sequential testing, whereby testing ceases for an individual student when sufficient information has been gathered [24]. This could be extrapolated to programmes of assessment whereby assessments cease when sufficient information is available on which to base a progress decision. The stakes of the decision would inform the strength and weight of the information required for a sufficiency of information. Just as for clinical decision-making, more of the same type of assessment may not improve progress decision-making, and a new perspective or an entirely new data source may be required. Instead of asking a student to repeat an assessment, a period of targeted observation, closer supervision or different assessments might be preferable to provide the required sufficiency of information. The nature of the extra information required will depend on what is already known about the individual, and may vary between 
students. The resulting variable assessment may generate concerns over fairness. In response, we would argue that fairness applies more to the robustness and defensibility of the progression decision, than to whether all students have been assessed identically.

\section{Aggregating conflicting information}

In clinical decision-making it is often necessary to weigh up conflicting pieces of evidence. Information gathered from history, examination, and investigations might, if considered in isolation, generate different lists of most likely diagnoses, each of which is held with uncertainty. However, when all the information is synthesised, the list of most likely diagnoses becomes clearer, and is held with increasing certainty [25]. Likewise in progression decision-making, considering single pieces of information generated from independent assessment events might generate different interpretations of a student's readiness to progress, but when these single pieces are synthesised, a more robust picture is constructed.

Synthesising data from multiple sources is possible for healthcare policy makers and practitioners [26-28]. Some data synthesis is done better mechanically or by algorithms than by individual clinicians [29], but better results may be achieved if fast and frugal heuristics are combined with actuarial methods [30]. In progression decision-making, combining scores using algorithms is possible [31], but equally plausible algorithms can lead to different outcomes [32, 33]. It may be easy simply to add test results together, but the result may not necessarily contribute the best information for decision-making purposes [31].

For clinical decision-making, strategies to improve decision-making include consideration of the health systems, including the availability of diagnostic decision support; second opinions; and audit [12]. A lack of checking and safeguards can contribute to errors [34]. Extrapolating this to progression decision-making, all assessment results should be considered in context, and decision support and decision review processes used.

\section{Screening tests and diagnostic tests}

Testing for disease in clinical practice can include a screening programme which requires combining tests, such as a screening test followed by a confirmatory test [35]. This can be extrapolated to progression decision-making [8], especially when data are sparse [36]. Generally, decision-making from clinical tests and educational assessments has to balance the sensitivity with the specificity of a test to help inform the decision. This is influenced by the purpose of the individual assessment and by the purpose of the assessment testing programme [8]. A screening programme for a disease will generally have a lower specificity and higher sensitivity, and a confirmatory test a lower sensitivity and higher specificity [35]; the predictive value of the test will be dependent on disease prevalence. Hence despite apparently excellent sensitivity and specificity, if the prevalence is very high or low, a testing programme can be non-contributory, or worse still, potentially harmful [8]. Such biases associated with educational assessment are discussed later.

\section{Risks associated with decisions}

The consequence and risk of incorrect clinical decisions, or deviation from optimal practice, can vary significantly from no clinically significant consequence to fatality [37]. Adverse consequences and risks occur even with optimal practice. Drugs have side effects, even when used appropriately, and sometimes these risks only come to light in clinical practice [38].

Healthcare educational institutions have a duty of care to take the interests of both students [39] and society [40] into account when making progression decisions on students. This dilemma of making decisions for individuals which have an impact not only on that individual, but also society, is explored further in the section on jury decision-making.

\section{When the decisions get tough}

Some decisions are made more difficult by the context, such as time-pressured decision-making in clinical practice [41] and high-stakes decision-making [42]. Even when correct answers are known, time-pressure increases uncertainty and inaccuracy in decision-making. It is important that educational institutions provide decision-makers with sufficient time to make robust decisions.

In addition, there are some questions that are impossible for an individual to resolve [34]. The diagnosis may not be straightforward because decisions may have significant consequences, and multiple specialised pieces of information or perspectives may need to be combined in order to advise optimal care. In these circumstances a second opinion may be requested [12]. Increasing the number of people considering the available data can be a better method than increasing the available data where this is not practical or safe. Multi-disciplinary teams, multi-disciplinary meetings, and case conferences can enhance patient care by using multiple people help to make decisions on aggregated information. In certain situations such group decision-making improves outcomes for patients [43].

One of the highest-stakes progression decisions on healthcare professional students is at graduation. The institution needs to recommend to a regulatory authority, and thereby society, that an individual is ready to enter the healthcare profession, and will be at least a minimally competent and safe practitioner. Given the potential high-stakes and complexity of the information to be considered, a panel is often part of decision-making in programmatic assessment [6]. The panellists bring different 
perspectives, and the longstanding assertion is that the collective is better than the component individuals [44].

\section{Comparing decision-making by individuals and groups}

When aggregating information, the average of many individuals' estimates can be close to reality, even when those individual estimates may be varied and lie far from it [44, 45]. This 'wisdom of the crowd' effect may not be true in all situations. When people work collectively rather than individually, this effect may be less apparent, as social interactions and perceived power differentials within groupings influence individual estimates. The resulting consensus produced is no more accurate, yet group members may perceive that they are making better estimates [45]. Further, the use of average, whether mean or median, to demonstrate this effect reflects the strength of how this effect works for numerical rather than narrative data, it is a mathematical effect [45]. The apparent reassurance that groups make better decisions than individuals may be misplaced when it comes to narrative data or collective decisions, unless precautions are taken.

Errors in decision-making can arise due to faults in knowledge, data gathering, information processing, and/ or verification [46]. There are biases and errors in individual's decision-making [10, 12, 15, 17, 18, 47], some of which are also evident in group decision-making [4850]. In comparing biases and errors in decisions made by individuals with those made by groups, some are attenuated, some amplified, and some reproduced, with no consistent pattern by categorisation [48]. These biases and errors, as they relate to individual and group progression decision-making, are shown in Table 1.

Groups, like individuals, undertake several processes in coming to a decision. The process of individuals gathering into a group can influence information recall and handling [48]. Although there is a significantly greater literature on individuals making decisions, groups making decisions can also be prone to biases [63] and this can arise from many sources [43]. In the context of progression decision-making, a group's initial preferences can persist despite available or subsequently disclosed information [64], a bias similar to premature closure in diagnostic decision-making [15]. Group members may be aware of interpersonal relationships within the decision group, such as the undue weight of a dominant personality, and these perceptions can influence an individual's contribution and discussion of information [48]. Persuasion and influence occur during discussion of a candidate assessment. Outliers who initially score candidates higher are more likely to reduce their score, while outliers who initially score the candidates lower are less likely to increase their score, with the result that consensus discussion is likely to lower candidate scores and therefore reduce the pass rate [65].

\section{A jury as an example of high-stakes decision-making by a group}

Jury decision-making is an example of a group making a high-stakes decision [48], that has been extensively researched and therefore could offer insights into progression decision-making. There is significant literature on decision-making, biases, and errors by jurors and/or juries $[49,50,66-76]$, including a summarising review [77]. There are similarities between the main purpose of the group of jurors considering all the evidence (with the aim of reaching a high-stakes verdict which is often a dichotomous guilty or not guilty verdict) and the main purpose of a group of decision-makers to consider all the assessment data (with the aim of reaching a high-stakes verdict of pass or fail). Jury decision-making, like progression decision-making, but unlike other group decision-making described, does not address a problem with a known correct answer [48, 66].

The relative contribution to the decision brought about by jurors and juries varies with the task [50]. As for clinical decision-making, there are heuristics which can improve the accuracy and efficiency of decisions, but when these produce less accurate or less efficient results, they are seen as biases. Susceptibility to variation and bias has been reported for simulated jurors and/or for some real juries, with factors that include [49, 50, 66-77]:

- Defendant and/or victim/plaintiff factors. This includes personal factors such as gender, race, physical appearance, economic background, personality, injuries, pre-trial publicity, disclosure of defendants prior record, freedom from selfincrimination, being individual or corporation, courtroom behaviour;

- Juror factors. This includes authoritarianism, proneness to be pro-conviction or pro-acquittal, age, gender, race, social background, recall of evidence, understanding of evidence, ignoring information as instructed, prior juror experience;

- Representative factors. This includes legal representation factors such as gender, written/verbal representation, clarity, style and efficiency of presentation;

- Evidence factors. This includes imagery of evidence (the more visual or more visually imaginable), order of presentation, nature of evidence;

- Crime factors. This includes the severity or type of crime;

- Judge factors. This includes the content of the instructions or guidance given;

- Jury membership factors. This includes the mix of aspects such as social background mix, racial mix. 


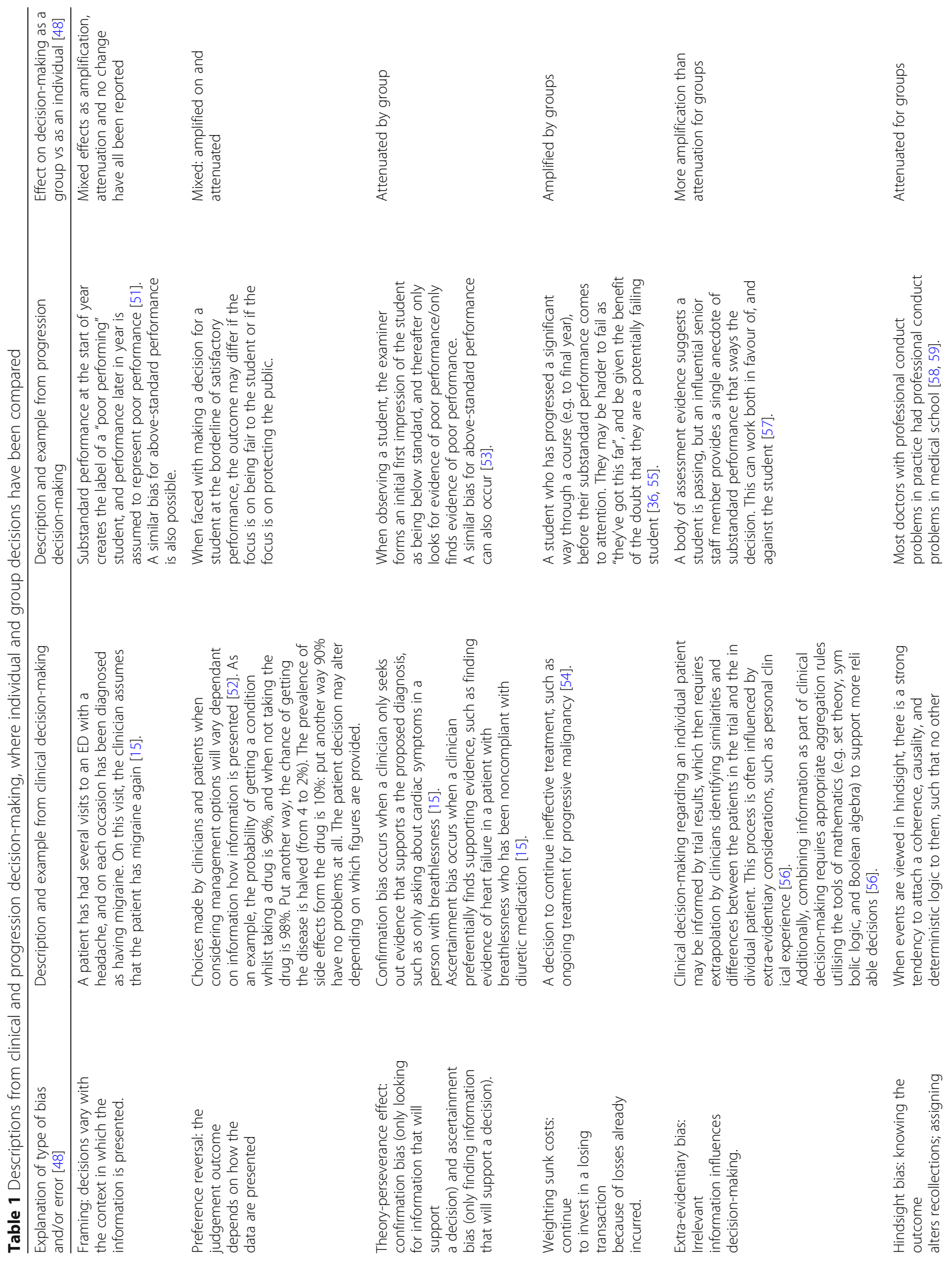




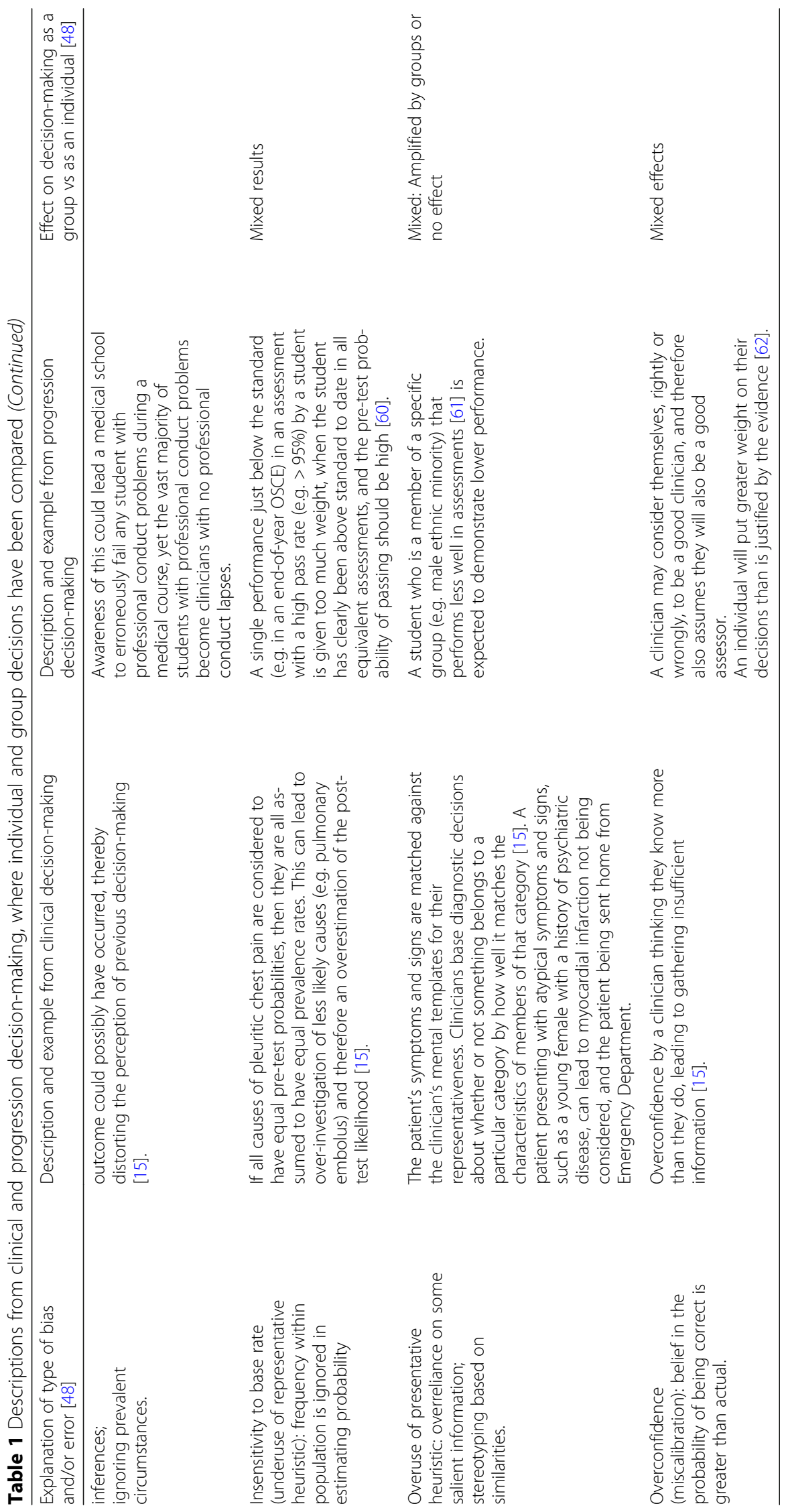


There are similarities in some of these factors in relation to progression decision-making. The ease of building a story influences both the decisions and the certainty in those decisions [71], akin to the availability bias. The juror bias due to initial impression $[67,75,77]$ is akin to anchoring. People may identify with similar people; a "people like us" effect may be present [78]. For progression decision-making some of these effects can be mitigated by anonymisation of students, as far as possible.

One difference between a jury and a panel making a progression decision, is that a juror does not provide information to their co-jurors. In contrast, a member of a progression decision panel might also have observed the student and can provide information. Lack of observation by the decision-makers can be a benefit in decision-making, as it removes a potential source of bias: a single anecdote can inappropriately contradict a robust body of evidence [57]. Additionally, bias produced by incorrect evidential recall is less of an issue than evidence presented to the panel for deliberation.

The programmatic assessment panel may be closer to a Supreme Court panel of judges rather than a jury of lay-people and peers, but there is little research on the decision-making and deliberations of panels of Supreme Court judges, which are conducted in closed-door meetings.

\section{Jury decision-making style}

Jury deliberation styles have been shown to be either evidence-driven, with pooling of information, or verdict-driven, which start with a verdict vote [68]. Evidence-driven deliberations take longer and lead to more consensus; verdict-driven deliberations tend to bring out opposing views in an adversarial way. When evidence-driven deliberations lead to a significant change of opinion, it is more likely to be related to a discussion of judge's instructions [68]. If the decision rules allow a majority vote verdict without consensus, a small but real effect is seen [77]: juries will stop deliberating once the required quorum is reached. Verdict voting can be subject to additional biases such as voting order where people alter their vote depending on the votes given to that point [77]. Group discussions are not without potential problems, in that they can generate extreme (more honest) positions. Ninety percent of all jury verdicts are in the direction of the first ballot majority [66], but a small and not insignificant number are swayed by deliberation. Once individuals state their individual decisions and rationales, diffusion of responsibility within a group may lead to riskier opinions being stated, and therefore riskier decisions being made [66].

Extrapolating this to the context of progression decision-making, an optimal approach is consensus decisions that are based on evidence, whilst attending to the rules and implementation of policy and process.

\section{Jury leadership}

Based on what we know about jury decision-making processes, the jury foreperson, the equivalent of the assessment progress panel chair, needs the skills to preserve open discourse, whilst maintaining good process in decision-making. The jury foreperson can be influential [77], and individual jurors can hold extreme views, though the process of jury selection usually mitigates against the selection of people with extreme views [66].

In choosing progress decision-makers, consideration should be given to the skills that are required to make high-stakes decisions based on aggregating information, rather than skills and knowledge relating to clinical practice.

\section{Jury leniency and failure to fail}

Is there a parallel between leniency towards the defendant and the failure to fail phenomenon [55]? Juries are instructed to presume innocence [67]: if one is to err in a verdict, leniency is preferred [79]. Legal decision-making has two components: the probability of supporting a decision, and threshold required to support that decision [66]. It is possible to support a decision but still retain a degree of doubt. The effect of standard of proof (reasonable doubt) required on juror and jury outcomes is significant $[69,77]$. If in doubt, a jury will favour acquittal $[48,63]$. Jury deliberations tend towards leniency [72, 75], with most leniency is accounted for by the requirement of standard of proof [72].

A similar effect has been observed in progression decision-making where, if in doubt, the decision is usually to pass the student [55]. The onus is on the jury to presume innocence unless finding guilt proven, but is the onus on the progress panel to find student competent proven? Too often this onus is erroneously misinterpreted as presuming competence unless finding incompetence proven. This can manifest as a discounting of multiple small pieces of evidence suggesting that competence has not yet been demonstrated [36].

\section{Suggestions to attend to in order to promote robustness of decisions made relating to student progression}

We now propose some good practice tips and principles that could be used by progression decision-makers. These are based on the previously outlined evidence from clinical decision-making and jury decision-making, and from additional relevant literature.

\section{Educational institutions, decision-making panels, and panellists should be aware of the potential for bias and error in progression decisions}

Being consciously aware of the possibility of bias is the first step to mitigate against it [19-21]. Such biases can occur both for individuals making decisions and for groups making decisions. Extrapolating from clinical decision-making, 
the challenge is raising awareness of the possibility of error by decision-makers [12]. Clinicians failing to recognise and disclose uncertainty in clinical decision-making is a significant problem $[47,80]$. However, even when there is uncertainty over student performance, decision panels still need to make a decision.

\section{Decisions should be made by appropriately selected decision-making panels}

Extrapolating from clinical decision-making, strategies to improve individual decision-making include promotion of expertise and metacognitive practice. A lack of expertise can contribute to errors [34], hence panel members should be selected with appropriate expertise in student outcome decision-making, rather than assessment content, and reflections on decision quality should include quality assurance in the way of feedback on decisions and training for decision-making. As such, the panel should be chosen on the basis of its ability to show metacognition in recognising bias, rather than status/seniority, familiarity with assessment content, or familiarity with the students.

Even a panel of experienced decision-makers is not without the potential for bias [81], but there are possible solutions that can be implemented at the policy, procedure and practice levels. Given the potential for professional and social interactions between students and staff, there should be policy, procedure, and practice documentation for potential conflicts of interest. If a decision-maker is conflicted for one or more students, then they should withdraw from decision-making. Potential conflicts of interest are far more likely to relate to individual decision-makers and individual students, and should be dealt with on a case-by-case basis guided by an appropriate policy. Examples of conflict might include more obvious relationships with family members, but also with mentors/mentees and those with a welfare role with students.

\section{Educational institutions should have publicly available policies, procedures, and practice documentation related to assessment events and the associated decision-making} Improving jury performance can be achieved through improving procedural issues [77]. These include, but are not necessarily limited to, the following: a thorough review of the facts in evidence, accurate jury-level comprehension of the judge's instructions, active participation by all jurors, resolution of differences through discussion as opposed to normative pressure, and systematic matching of case facts to the requirements for the various verdict options. Likewise, from the perspective of a progression panel decision, these would equate to: a thorough review of the information provided, accurate comprehension of the policy, active participation by all panel members, resolution of differences through discussion and consensus, and systematic matching of information to the requirements for the assessment purpose and outcomes. While some might argue that these components are already implicit in many decision-making processes, the quality of decision-making may be improved if such components are made more explicit.

\section{Panels and panellists should be provided with sufficient information for the decision required}

Group discussions can improve recall of information [48], and some of the benefit of juries, as opposed to jurors, relates to improved recall by a group compared to individuals $[66,67,74]$. Multiple jurors produce less complete but more accurate reports than individual jurors [66].

In progression decision-making, it is unlikely that panellists will have to rely on recall for specifics of information or policy when making decisions, but the panel will need to decide if they have sufficient information (quality and quantity) in order to reach a decision for an individual student. Where there is insufficient information, but more may become available, this should be specifically sought [36], and a decision deferred. Where further information will not become available, the question should then turn to where the onus of the burden of proof lies.

\section{Panels and panellists should work to optimise their information synthesis and reduce bias}

The act of deliberation and discussion within groups attenuates many of the biases and errors of individuals [48], as outlined in Table 1. Some biases, such as extra-evidentiary bias, can be amplified in group decision-making, an example being where provision of an anecdote could unduly influence a group's decision [57].

Progression decision-making requires consideration of all information and the context, with decision support and decision review. External review might extend beyond just reviewing the decisions, to an external review of the underlying panel process, procedures, and practices. Not every panel discussion needs external review, but policy review associated with regular external observation would be appropriate.

\section{Panellists should reach decisions by consensus}

Consensus decision-making rather than voting avoids adversarial decision-making. In an attempt to produce fairness within a courtroom, facts are uncovered and presented in an adversarial manner, with information being questioned by opposing legal representation [67]. This results in the appearance of evidential unreliability and contentiousness. Similarly, when faced with information presented in an adversarial way, progression decision-making panels might view the information as being less reliable, and therefore insufficient to make a robust decision. 


\section{The burden of proof should lie with a proven demonstration of competence}

For high-stakes pass/fail decision-making, the standard of proof should be proof that the student's competence is at a satisfactory standard to progress. The assumption is often that the student is competent, until proved otherwise. In contrast to "innocent until proven guilty", we suggest students should be regarded as incompetent until proven competent, reflecting the duty for healthcare educational institutions to protect society [40].

The predictive value of a test result is affected by the pre-test probability or prevalence, even though sensitivity and specificity may not change. This pre-test probability or prevalence of passing should increase as a cohort progresses through the course, as less able students are removed. Therefore, incorrect pass/fail decisions are relatively more likely to be false fails (true passes) than false passes (true fails), and when an assessment is equivocal, it is more likely that the student is satisfactory than not. However, as a student progresses through the course and the opportunities for further assessment are reduced. As graduation nears, the stakes and impact of an incorrect pass/fail decision increases. Although pre-test probability or prevalence considerations would favour passing the student, the duty of the institution to meet the needs and expectations of society should override this.

\section{Conclusion}

We provide a call for metacognition in progression decision-making. We should be mindful of the strengths of combining several pieces of information to construct an accurate picture of a student, but should also be mindful of the sources of bias in making decisions. While we acknowledge that many institutions may already be demonstrating good practice, awareness of biases and the suggested process outlined in this paper can serve as part of a quality assurance checklist to ensure hidden biases and decision-making errors are minimised. Drawing on one's experience of clinical decision-making and an understanding of jury decision-making can assist in this.

\section{Acknowledgements}

Kelby Smith-Han and Fiona Hyland (University of Otago) for providing constructive comments on a draft of the manuscript.

\section{Funding}

No funding sources to declare

\section{Availability of data and materials}

All data generated or analysed during this study are included in this published article.

\section{Authors' contributions}

Both MT and TW developed the concept. MT wrote the first draft. Both MT and TW developed subsequent drafts and responded to reviewers comment. Both authors read and approved the final manuscript.
Ethics approval and consent to participate

Not applicable as this invited commentary.

Consent for publication

Not applicable.

Competing interests

The authors declare that they have no competing interests.

\section{Publisher's Note}

Springer Nature remains neutral with regard to jurisdictional claims in published maps and institutional affiliations.

\section{Author details}

'Department of Medicine, University of Otago Wellington, Wellington, New Zealand. ${ }^{2}$ University of Otago Christchurch, Christchurch, New Zealand.

Received: 8 October 2018 Accepted: 30 April 2019

Published online: 30 May 2019

References

1. Downing SM. Validity: on the meaningful interpretation of assessment data. Med Educ. 2003;37(9):830-7.

2. Downing SM. Reliability: on the reproducibility of assessment data. Med Educ. 2004;38(9):1006-12.

3. Cook DA, Beckman TJ. Current concepts in validity and reliability for psychometric instruments: theory and application. Am J Med. 2006;119(2):166. e7-16.

4. Downing SM. Item response theory: applications of modern test theory in medical education. Med Educ. 2003;37(8):739-45.

5. Hodges B. Assessment in the post-psychometric era: learning to love the subjective and collective. Med Teach. 2013;35(7):564-8.

6. Wilkinson TJ, Tweed MJ. Deconstructing programmatic assessment. Adv Med Educ Pract. 2018;9:191-7.

7. Van Der Vleuten CP, Schuwirth LW. Assessing professional competence: from methods to programmes. Med Educ. 2005;39(3):309-17.

8. Tweed M, Wilkinson T. Diagnostic testing and educational assessment. Clin Teach. 2012;9(5):299-303.

9. Hall KH. Reviewing intuitive decision-making and uncertainty: the implications for medical education. Med Educ. 2002;36(3):216-24.

10. Elstein AS, Schwarz A. Clinical problem solving and diagnostic decision making: selective review of the cognitive literature. BMJ. 2002;324(7339):729-32.

11. Croskerry P. The theory and practice of clinical decision-making. Can J Anesth/J CanAnesth. 2005;52:R1-8.

12. Berner ES, Graber ML. Overconfidence as a cause of diagnostic error in medicine. Am J Med. 2008;121(5):S2-S23.

13. Elstein AS. Thinking about diagnostic thinking: a 30-year perspective. Adv Health Sci Educ. 2009;14(1):7-18.

14. Croskerry P. A universal model of diagnostic reasoning. Acad Med. 2009:84(8):1022-8

15. Croskerry P. Achieving quality in clinical decision making: cognitive strategies and detection of Bias. Acad Emerg Med. 2002;9(11):1184-204.

16. Croskerry P. The importance of cognitive errors in diagnosis and strategies to minimize them. Acad Med. 2003;78(8):775-80.

17. Redelmeier DA. The cognitive psychology of missed diagnoses. Ann Intern Med. 2005;142(2):115-20.

18. Redelmeier DA, et al. Problems for clinical judgement: introducing cognitive psychology as one more basic science. Can Med Assoc J. 2001;164(3):358-60.

19. Mamede $\mathrm{S}$, et al. Exploring the role of salient distracting clinical features in the emergence of diagnostic errors and the mechanisms through which reflection counteracts mistakes. BMJ Qual Saf. 2012;21(4):295-300.

20. Graber ML, et al. Cognitive interventions to reduce diagnostic error: a narrative review. BMJ Qual Saf. 2012;21:535-57.

21. Croskerry P, Singhal G, Mamede S. Cognitive debiasing 2: impediments to and strategies for change. BMJ Qual Saf. 2013;22(Suppl 2):ii65-72.

22. Cassel CK, Guest JA. Choosing wisely: helping physicians and patients make smart decisions about their care. JAMA. 2012;307(17):1801-2.

23. Levinson W, et al. 'Choosing wisely': a growing international campaign. BMJ Qual Saf. 2015;24(2):167-74.

24. Pell G, et al. Advancing the objective structured clinical examination: sequential testing in theory and practice. Med Educ. 2013;47(6):569-77. 
25. Diamond GA, Forrester JS. Metadiagnosis:: An epistemologic model of clinical judgment. Am J Med. 1983;75(1):129-37.

26. Dixon-Woods $M$, et al. Synthesising qualitative and quantitative evidence: a review of possible methods. J Health Serv Res Policy. 2005;10(1):45-53.

27. Lucas PJ, et al. Worked examples of alternative methods for the synthesis of qualitative and quantitative research in systematic reviews. BMC Med Res Methodol. 2007;7(1):4.

28. Mays N, Pope C, Popay J. Systematically reviewing qualitative and quantitative evidence to inform management and policy-making in the health field. J Health Serv Res Policy. 2005;10(1_suppl):6-20.

29. Grove WM, et al. Clinical versus mechanical prediction: a meta-analysis. Psychol Assess. 2000;12(1):19-30.

30. Katsikopoulos KV, et al. From Meehl to fast and frugal heuristics (and Back) New Insights into How to Bridge the Clinical—Actuarial Divide. Theory Psychol. 2008;18(4):443-64

31. Schuwirth $L$, van der Vleuten C, Durning S. What programmatic assessment in medical education can learn from healthcare. Perspect Med Educ. 2017;6(4):211-5.

32. Wilson I. Combining assessment scores-a variable feast. Med Teach. 2008; 30(4):428-30.

33. Tweed M. Station score aggregation and pass/fail decisions for an OSCE: A problem, a solution and implementation. Focus Health Professional Educ: Multi-disciplinary J. 2008;10(1):43-9.

34. Gandhi TK, et al. Missed and delayed diagnoses in the ambulatory setting: a study of closed malpractice claims. Ann Intern Med. 2006;145(7):488.

35. Deeks JJ. Systematic reviews of evaluations of diagnostic and screening tests. BMJ. 2001;323(7305):157-62.

36. Wilkinson TJ, et al. Joining the dots: conditional pass and programmatic assessment enhances recognition of problems with professionalism and factors hampering student progress. BMC Medical Education. 2011;11(1):29.

37. Kalra J, Kalra N, Baniak N. Medical error, disclosure and patient safety: a global view of quality care. Clin Biochem. 2013:46:1161-9.

38. Guo JJ, et al. A review of quantitative risk-benefit methodologies for assessing drug safety and efficacy-report of the ISPOR risk-benefit management working group. Value Health. 2010;13(5):657-66.

39. Tweed M, Miola J. Legal vulnerability of assessment tools. Med Teach. 2001;23(3):312-4.

40. New Zealand Legislation, Health Practitioners Competence Assurance Act. 2003: http://www.legislation.govt.nz.

41. Lighthall GK, Vazquez-Guillamet C. Understanding decision making in critical care. Clin Med Res. 2015:13(3-4):156-68.

42. Klein G. Naturalistic decision making. Hum Factors. 2008;50(3):456-60.

43. Dew $\mathrm{K}$, et al. Cancer care decision making in multidisciplinary meetings. Qual Health Res. 2015;25(3):397-407.

44. Galton F. Vox populi (the wisdom of crowds). Nature. 1907:75(7):450-1.

45. Lorenz J, et al. How social influence can undermine the wisdom of crowd effect. Proc Natl Acad Sci. 2011;108(22):9020-5.

46. Graber MI FNGR. Dlagnostic error in internal medicine. Arch Intern Med. 2005:165(13):1493-9.

47. Croskerry P, Norman G. Overconfidence in clinical decision making. Am J Med. 2008:121(5A):S24-S29.

48. Kerr NL, MacCoun RJ, Kramer GP. Bias in judgment: comparing individuals and groups. Psychol Rev. 1996;103(4):687.

49. Sommer KL, Horowitz IA, Bourgeois MJ. When juries fail to comply with the law: biased evidence processing in individual and group decision making. Personal Soc Psychol Bull. 2001;27(3):309-20.

50. Kerr NL, Niedermeier KE, Kaplan MF. Bias in jurors vs bias in juries: new evidence from the SDS perspective. Organ Behav Hum Decis Process. 1999;80(1):70-86.

51. MacDougall $\mathrm{M}$, et al. Halos and horns in the assessment of undergraduate medical students: a consistency-based approach. J Appl Quant Methods. 2008;3(2):116-28.

52. Bleichrodt $H$, Pinto Prades JL. New evidence of preference reversals in health utility measurement. Health Econ. 2009:18(6):713-26.

53. Keating J, Dalton M, Davidson M. Assessment in clinical education. In: Delany C, Molloy E, editors. Clinical Education in the Health Professions: an Educator's Guide. Australia: Churchill Livingstone; 2009. p.147-172.

54. Braverman JA, Blumenthal-Barby JS. Assessment of the sunk-cost effect in clinical decision-making. Soc Sci Med. 2012;75(1):186-92.

55. Dudek NL, Marks MB, Regehr G. Failure to fail: the perspectives of clinical supervisors. Acad Med. 2005;80(10):S84-7.
56. Chin-Yee B, Upshur R. Clinical judgement in the era of big data and predictive analytics. J Eval Clin Pract. 2018;24(3):638-45.

57. Tweed MJ, Thompson-Fawcett M, Wilkinson TJ. Decision-making bias in assessment: the effect of aggregating objective information and anecdote. Med Teach. 2013;35(10):832-7.

58. Papadakis MA, et al. Unprofessional behavior in medical school is associated with subsequent disciplinary action by a state medical board. Acad Med. 2004;79(3):244-9.

59. Papadakis MA, et al. Disciplinary action by medical boards and prior behavior in medical school. N Engl J Med. 2005;353(25):2673-82.

60. van der Vleuten $\mathrm{C}$. Validity of final examinations in undergraduate medical training. BMJ: Br Med J. 2000;321(7270):1217-9.

61. Dewhurst NG, et al. Performance in the MRCP (UK) examination 2003-4: analysis of pass rates of UK graduates in relation to self-declared ethnicity and gender. BMC Med. 2007;5(1):8.

62. Tweed M, Ingham C. Observed consultation: confidence and accuracy of assessors. Adv Health Sci Educ. 2010;15(1):31-43.

63. Lipshitz $R$, et al. Taking stock of naturalistic decision making. J Behav Decis Mak. 2001;14(5):331-52.

64. Stasser $\mathrm{G}$, Titus W. Pooling of unshared information in group decision making: biased information sampling during discussion. J Pers Soc Psychol. 1985:48(6):1467-78.

65. Herriot $P$, Chalmers $C$, Wingrove J. Group decision making in an assessment Centre. J Occup Organ Psychol. 1985;58(4):309-12.

66. Wasserman DT, Robinson JN. Extra-legal influences, group processes, and jury decision-making: a psychological perspective. NC Cent LJ. 1980;12:96-157.

67. Kaplan MF, Miller LE. Reducing the effects of juror bias. J Pers Soc Psychol. 1978;36(12):1443-55.

68. Pennington N, Hastie R. Practical implications of psychological research on juror and jury decision making. Personal Soc Psychol Bull. 1990;16(1):90-105.

69. Thomas EA, Hogue A. Apparent weight of evidence, decision criteria, and confidence ratings in juror decision making. Psychol Rev. 1976;83(6):442-65.

70. Mazzella R, Feingold A. The effects of physical attractiveness, race, socioeconomic status, and gender of defendants and victims on judgments of mock jurors: a meta-analysis. J Appl Soc Psychol. 1994:24(15):1315-38.

71. Pennington N, Hastie R. Explaining the evidence: tests of the story model for juror decision making. J Pers Soc Psychol. 1992:62(2):189-206.

72. MacCoun RJ, Kerr NL. Asymmetric influence in mock jury deliberation: Jurors' bias for leniency. J Pers Soc Psychol. 1988:54(1):21-33.

73. Sommers SR. Race and the decision making of juries. Leg Criminol Psychol. 2007:12(2):171-87.

74. Visher CA. Juror decision making: the importance of evidence. Law Hum Behav. 1987;11(1):1-17

75. MacCoun RJ. Experimental research on jury decision-making. Science. 1989; 244(4908):1046-50.

76. Casper JD, Benedict K, Perry JL. Juror decision making, attitudes, and the hindsight bias. Law Hum Behav. 1989;13(3):291-310.

77. Devine DJ, et al. Jury decision making: 45 years of empirical research on deliberating groups. Psychol Public Policy Law. 2001;7(3):622-727.

78. Smith HJ, Spears R, Oyen M. " people like us": the influence of personal deprivation and group membership salience on justice evaluations. J Exp Soc Psychol. 1994;30(3):277-99.

79. Rizzolli M, Saraceno M. Better that ten guilty persons escape: punishment costs explain the standard of evidence. Public Choice. 2013;155(3-4):395-411.

80. Katz J. Why doctors don't disclose uncertainty. Hastings Cent Rep. 1984 14(1):35-44

81. Danziger S, Levav J, Avnaim-Pesso L. Extraneous factors in judicial decisions. Proc Natl Acad Sci. 2011;108(17):6889-92.

Ready to submit your research? Choose BMC and benefit from:

- fast, convenient online submission

- thorough peer review by experienced researchers in your field

- rapid publication on acceptance

- support for research data, including large and complex data types

- gold Open Access which fosters wider collaboration and increased citations

- maximum visibility for your research: over $100 \mathrm{M}$ website views per year

At $\mathrm{BMC}$, research is always in progress.

Learn more biomedcentral.com/submissions 